\title{
1,25-Dihydroxyvitamin D3 Treatment Delays Cellular Aging in Human Mesenchymal Stem Cells while Maintaining Their Multipotent Capacity
}

\author{
Barbara Klotz ${ }^{1}$, Birgit Mentrup ${ }^{1}$, Martina Regensburger ${ }^{1}$, Sabine Zeck ${ }^{1}$, Jutta Schneidereit ${ }^{1}$, Nicole \\ Schupp $^{2}$, Christian Linden ${ }^{3}$, Cornelia Merz ${ }^{1}$, Regina Ebert ${ }^{1}$, Franz Jakob ${ }^{1 *}$
}

1 Orthopedic Center for Musculoskeletal Research, University of Würzburg, Würzburg, Germany, 2 Institute of Pharmacology and Toxicology, University of Würzburg, Würzburg, Germany, 3 Institute for Virology and Immunobiology, University of Würzburg, Würzburg, Germany

\begin{abstract}
1,25-dihydroxyvitamin D3 $(1,25 \mathrm{D} 3)$ was reported to induce premature organismal aging in fibroblast growth factor-23 (Fgf23) and klotho deficient mice, which is of main interest as 1,25D3 supplementation of its precursor cholecalciferol is used in basic osteoporosis treatment. We wanted to know if 1,25D3 is able to modulate aging processes on a cellular level in human

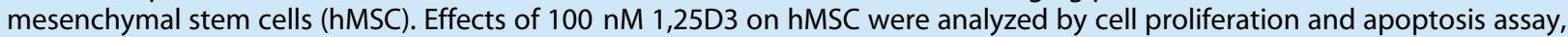
$\beta$-galactosidase staining, VDR and surface marker immunocytochemistry, RT-PCR of 1,25D3-responsive, quiescence- and replicative senescence-associated genes. 1,25D3 treatment significantly inhibited hMSC proliferation and apoptosis after $72 \mathrm{~h}$ and delayed the development of replicative senescence in long-term cultures according to $\beta$-galactosidase staining and P16 expression. Cell morphology changed from a fibroblast like appearance to broad and rounded shapes. Long term treatment did not induce lineage commitment in terms of osteogenic pathways but maintained their clonogenic capacity, their surface marker characteristics (expression of CD73, CD90, CD105) and their multipotency to develop towards the chondrogenic, adipogenic and osteogenic pathways. In conclusion, 1,25D3 delays replicative senescence in primary hMSC while the pro-aging effects seen in mouse models might mainly be due to elevated systemic phosphate levels, which propagate organismal aging.
\end{abstract}

Citation: Klotz B, Mentrup B, Regensburger M, Zeck S, Schneidereit J, et al. (2012) 1,25-Dihydroxyvitamin D3 Treatment Delays Cellular Aging in Human Mesenchymal Stem Cells while Maintaining Their Multipotent Capacity. PLoS ONE 7(1): e29959. doi:10.1371/journal.pone.0029959

Editor: Gian Paolo Fadini, University of Padova, Italy

Received February 4, 2011; Accepted December 9, 2011; Published January 5, 2012

Copyright: (c) 2012 Klotz et al. This is an open-access article distributed under the terms of the Creative Commons Attribution License, which permits unrestricted use, distribution, and reproduction in any medium, provided the original author and source are credited.

Funding: This work was supported by the German Research Foundation DFG (JA 504/8-1; http://www.dfg.de). The funders had no role in study design, data collection and analysis, decision to publish, or preparation of the manuscript.

Competing Interests: The authors have declared that no competing interests exist.

*E-mail: f-jakob.klh@uni-wuerzburg.de

\section{Introduction}

The biologically active metabolite of vitamin $\mathrm{D}, 1,25$-dihydroxyvitamin D3 $(1,25 \mathrm{D} 3)$ is synthesized from precursors by sequential hydroxylations in the liver (25-hydroxylase) and kidney $(1 \alpha-$ hydroxylase) [1-2]. 1,25D3 is involved in calcium and phosphate homeostasis through its effects on target organs such as intestine, kidney, parathyroid gland and bone [3-4]. There is also some evidence for a close association between hypervitaminosis $\mathrm{D}$ and accelerated aging in mice models [5]. Combined binding of the phosphatonin FGF23 and the longevity-associated gene product Klotho to the FGF receptor type 1 exerts FGF23 specific signaling [6]. Both, Fgf23-deficient $\left(\mathrm{Fg} 2 \mathrm{2}^{-/-}\right)$and klotho $\left(\mathrm{kl}^{-/-}\right)$deficient mice, show a similar phenotype displaying growth retardation, growth plate abnormalities, highly elevated serum phosphate and serum 1,25D3 levels, infertility, arteriosclerosis, premature aging and a shortened lifespan [7-8]. Ablation of the vitamin D activation pathway by additional knockout of the $1 \alpha$-hydroxylase gene reverses anomalies in $F g f 23^{-/-}$mice [9] and genetic inactivation of $1 \alpha$-hydroxylase gene in $\mathrm{kl}^{-/-} / 1 \mathrm{a}(\mathrm{OH})$ ase $e^{-/-}$mice reversed or abated the typical features observed in $\mathrm{kl}^{-/-}$mice [10]. Furthermore it was demonstrated that in $\mathrm{Fg}_{2} 23^{-/-}$mice with a non-functioning vitamin $\mathrm{D}$ receptor (VDR) the bone, mineral and glucose homeostasis could be rescued [11]. Therefore, interventions affecting the vitamin $\mathrm{D}$ responsive signal transduction seem to be closely linked to aging phenomena [5]. In contrast to these results, which linked VDR-dependent signaling to premature aging, it has been recently shown that VDR deficient mice develop premature aging phenomena, indicating that VDRsignaling might have anti-aging effects [12]

Mammalian aging is a complex biological process that can be defined as a progressive deterioration of physiological functions, as a decline of the functionality and regenerative capacity of all tissues and organs. It is accompanied by age-related diseases like arteriosclerosis, dementia, and osteoporosis [13]. Monogenetic mouse models and diseases in humans indicate that besides other mechanisms DNA and protein damage accumulation is associated with premature aging. Oxidative stress caused by reactive oxygen species (ROS) induces damage of the genome and proteome and promotes aging [14-15]. An imbalance between ROS production and detoxification leads to an increase of the ROS induced damage. The neutralization of ROS by a series of antioxidative enzymes and small molecules, e. g. superoxide dismutases or glutathione peroxidases, is an important segment of detoxification which also modulates the aging process [16]. 
Bone marrow derived human mesenchymal stem cells (hMSG) are multipotent and can give rise to mesenchymal tissues like bone, cartilage, and fat. They are a principal source of regeneration and healing and may be valuable tools for cell based regenerative therapies [17-18].

The aim of the present study was to characterize the effect of $1,25 \mathrm{D} 3$ on aging processes in hMSC. This was investigated in a series of experiments including e.g. RT-PCR analysis of quiescence- and senescence-associated genes, proliferation pace and ROS accumulation. Our hypothesis was that 1,25D3 is not a pro-aging compound at the cellular level and after having performed pilot studies we extended the hypothesis in that it might even delay cellular senescence.

\section{Results}

\section{VDR immunocytochemistry and expression of 1,25D3} responsive genes in hMSC

The effect of 1,25D3 on mRNA expression of responsive genes in hMSC was analyzed after stimulating cells from three donors for $24 \mathrm{~h}$. To validate the method and to analyze regulation in hMSC we first amplified genes, known to be affected by 1,25D3 [19]. RT-PCR analysis resulted in an enhanced expression of 24hydroxylase (CYP24A1), osteocalcin $(O C)$ and osteopontin $(O P \mathcal{N})$ in all three donors compared to unstimulated control cells (Fig. 1A/ B). In summary, 1,25D3 modulates the expression of 1,25D3 responsive genes in $\mathrm{hMSC}$.

Incubation of $\mathrm{hMSC}$ for $24 \mathrm{~h}$ with the VDR ligand 1,25D3 leads to a translocation of the liganded receptor into the nucleus, which was demonstrated by immunostaining with an antibody against human VDR (Fig. 1C). The intensive staining of a region overlapping with the nucleus, showed by DAPI staining, confirmed the nuclear translocation of liganded receptor in hMSC.

\section{Immunophenotype of hMSC treated with or without $1,25 \mathrm{D} 3$ at P1 and P3}

The immunophenotype of hMSC was screened by surface antigen characterization using flow cytometry analysis (Fig. S1). To delineate possible phenotypic changes over time we analyzed $\mathrm{P} 1$ and $\mathrm{P} 3$ of $1,25 \mathrm{D} 3$ treated hMSG compared to untreated hMSC. Flow cytometry was not able to distinguish any differences between 1,25D3 stimulated hMSG and control hMSG at P1 and P3. Both, 1,25D3 treated hMSC and untreated cells, were negative for the hematopoietic markers CD34, GD45 and HLADR (Fig. S1, right panels), and positive for the mesenchymal markers CD73, CD90 and CD105 (Fig. S1, left panels). Fig. S1

A

C

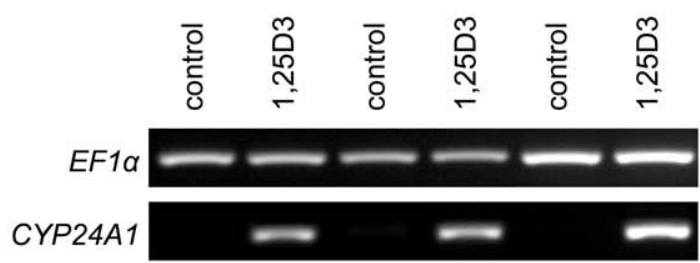

$1,25 \mathrm{D} 3$

B

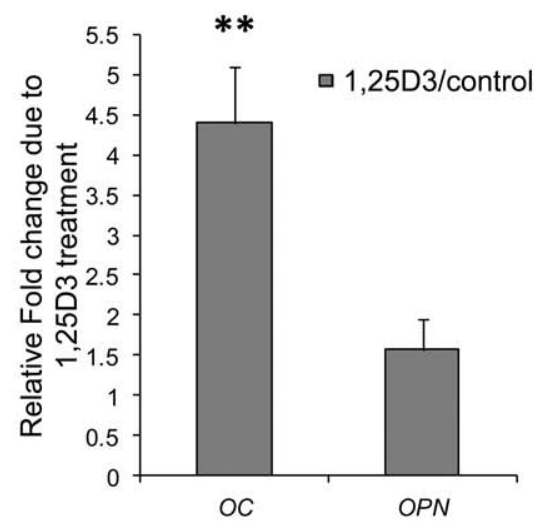

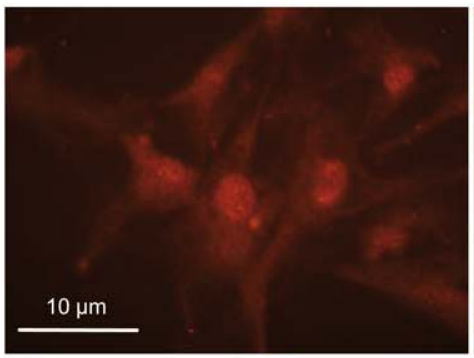
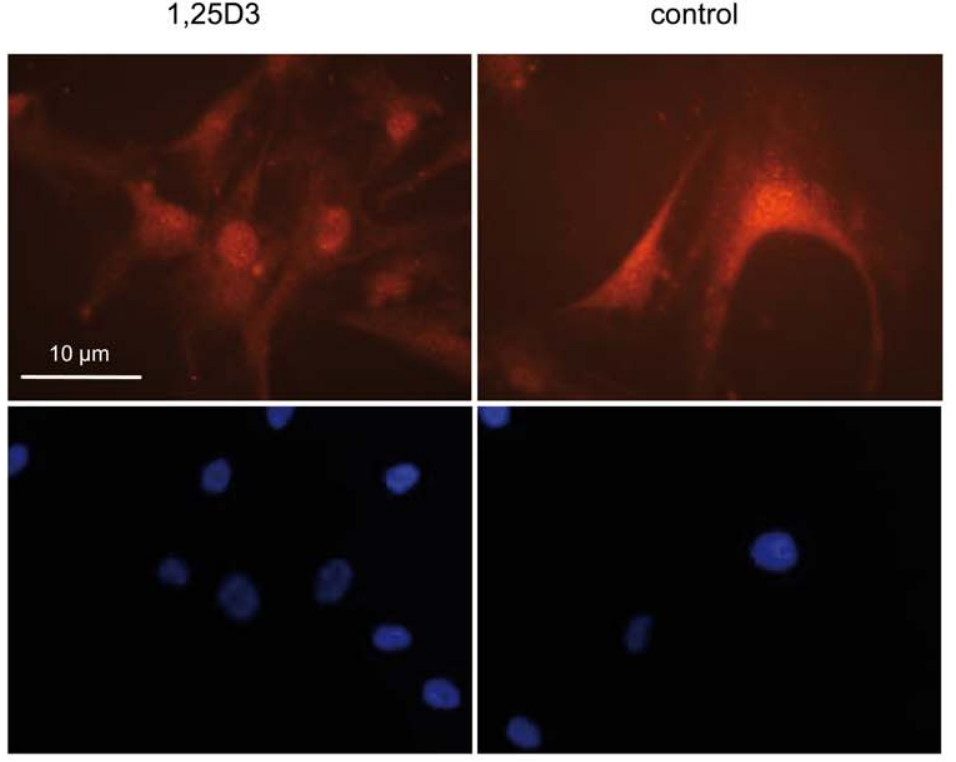

Figure 1. 1,25D3 response in hMSC. A/B 1,25D3 stimulation of hMSC resulted in a strong increase of CYP24A1 expression in all three donors. Control cells showed no CYP24A1 expression, therefore densitometric quantification was not possible (A). The induction of OC expression is considerable and significant ( ${ }^{* *}, \mathrm{p}<0.01$, student's t-test), the OPN expression is less intense. Densitometric quantification of $O C$ and OPN expression was performed. For each donor the Fold Change was calculated by comparing the expression of 1,25D3 treated cells with control cells. The results were obtained from three independent donors and are shown as mean+SEM (B). C Immunostaining of VDR in hMSC after stimulation with 1,25D3 for $24 \mathrm{~h}$. Stimulated cells show an increased localization of VDR in the nucleus, whereas the staining of the control cells is more diffuse (upper panel). Counterstaining with DAPI displays the localization of the nucleus (lower panel). One representative experiment is shown. Experiments were performed three times.

doi:10.1371/journal.pone.0029959.g001 
shows 1,25D3 treated hMSC and control cells gated for CD73, CD90 and CD105 positivity. The expression of CD73, CD90 and CD105 of 1,25D3 treated hMSC and untreated cells was between $88.9 \%$ and $98.7 \%$.

\section{Clonogenic capacity of 1,25D3 treated and untreated hMSC}

1,25D3 stimulated and control hMSG were assayed for colony forming unit (CFU) frequency at $\mathrm{P} 1$ and $\mathrm{P} 3$, using cells from three donors $(\mathrm{P} 3)$ and five independent donors $(\mathrm{P} 1)$, respectively. No difference was observed between the two groups in terms of colony numbers at P1 and P3 (Fig. S2). The CFU frequency was highly donor-dependent and ranged from 318-1352 CFUs per 800 seeded hMSC at P1 and from 412-709 CFUs per 800 seeded cells at P3. Neither P1 nor P3 showed a significant correlation between $1,25 \mathrm{D} 3$ treatment and the number of CFUs. However, a nonsignificant decrease in CFUs could be observed in sets of cultures established at $\mathrm{P} 3$ in comparison to $\mathrm{P} 1$.
Short term effects of 1,25D3 on proliferation and apoptosis in hMSC

Stimulation of hMSG from three donors for 24, 48 and $72 \mathrm{~h}$ with 1,25D3 revealed similar effects on proliferation and apoptosis. 1,25D3 treatment of hMSC leads to a significant inhibition of cell proliferation after $48 \mathrm{~h}(17 \%$ reduction; **, $\mathrm{p}<0.01)$ and $72 \mathrm{~h}(27 \%$ reduction; ***, $\mathrm{p}<0.001)$ (Fig. 2A). Only a marginal inhibition of cell proliferation was noted after $24 \mathrm{~h}$ treatment. The apoptosis of hMSC was inhibited by $1,25 \mathrm{D} 3$ treatment after $48 \mathrm{~h}(12 \%$ reduction) and $72 \mathrm{~h}(23 \%$;, $\mathrm{p}<0.05)$, respectively. After $24 \mathrm{~h}$ only minor effects on apoptosis could be observed (Fig. 2B).

Growth rate of hMSC permanently treated with 1,25D3

The proliferation capacities (cumulative population doublings, CPDs) of hMSC grown under permanent 1,25D3 treatment showed lower CPDs (gray bar) versus control cells (black bar) (Fig. 2C). The proliferation rate of control hMSG was somewhat

\section{A}

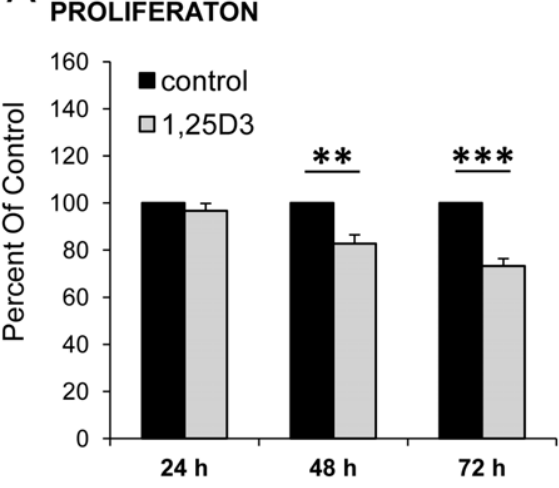

B

APOPTOSIS

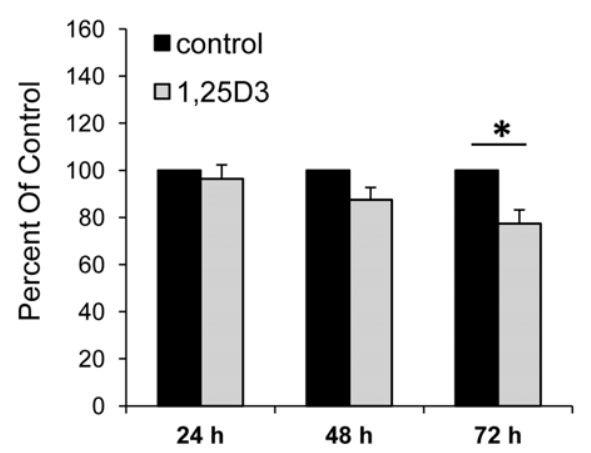

C cumulative Population doublings
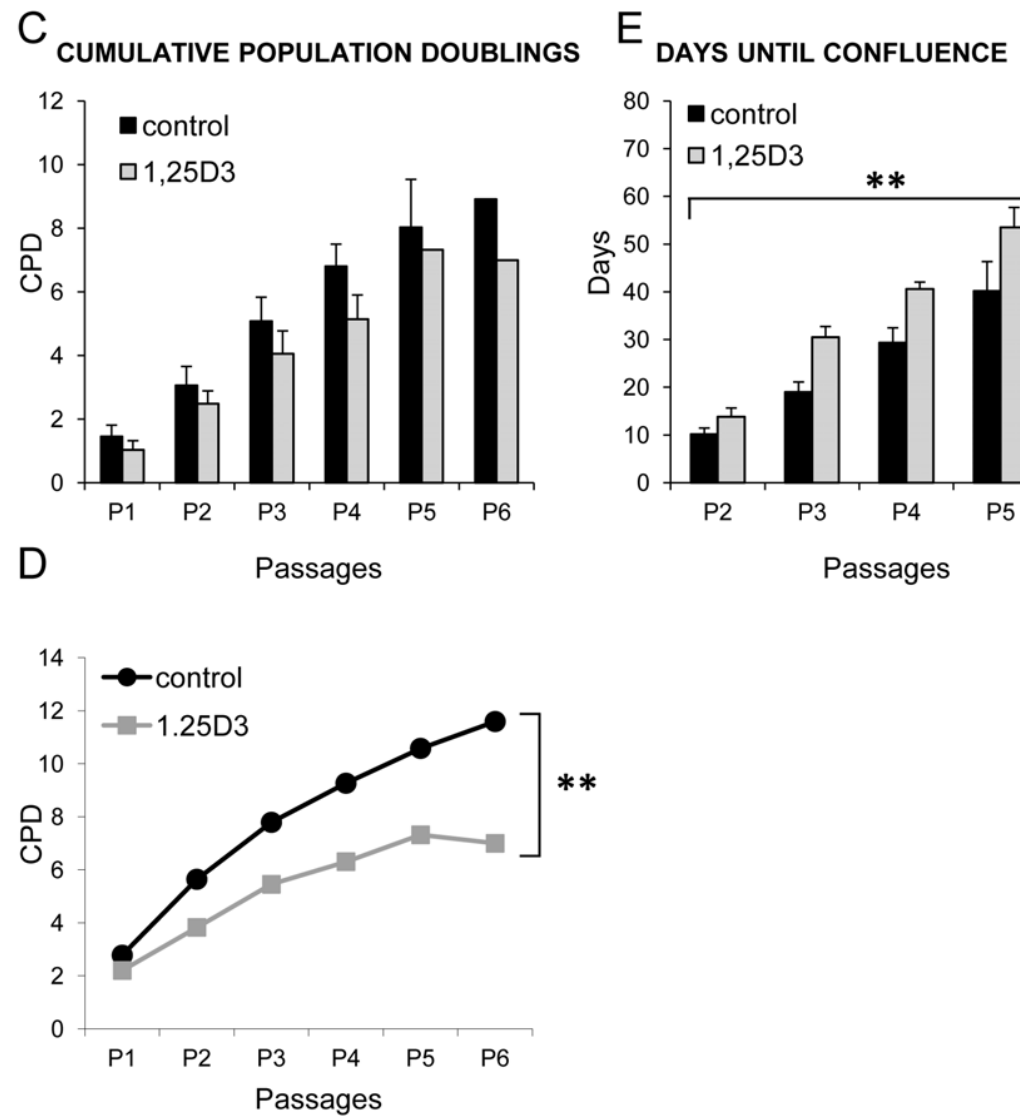

Figure 2. 1,25D3 effects on proliferation, apoptosis and cumulative population doublings. A/B Measurement of proliferation capacity and apoptosis induction of hMSC from three different donors after stimulation with 1,25D3 for 24,48 and $72 \mathrm{~h}$. The proliferation rate was decreased time-dependently after 1,25D3 treatment (gray bars) compared to control cells (black bars), with significant effects after $48 \mathrm{~h}$ and $72 \mathrm{~h}(\mathrm{~A}) .1,25 \mathrm{D} 3$

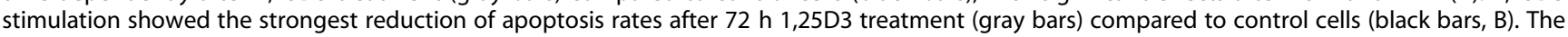
results are shown as mean+SEM of three independent experiments, each normalized to its control and performed in triplicates. Cells from three different donors were used. $\left({ }^{*}, \mathrm{p}<0.05 ;^{* *}, \mathrm{p}<0.01 ;^{* * *}, \mathrm{p}<0.001\right.$, student's t-test). C The growth rates of cells were determined by population doublings at each subcultivation. Cumulative population doubling (CPD) was first determined for P2. Population doublings were observed for up to six cell passages. Persistent 1,25D3 supplementation resulted in a reduction of population doublings (gray bar), but the difference was not statistically significant. Independent experiments were performed using hMSC from several human donors. Control: P1, P2, $n=6 ; P 3, P 4, n=5 ; P 5, n=3 ; P 6, n=2$. 1,25D3: $P 1, P 2, n=6 ; P 3, P 4, n=4 ; P 5, P 6, n=1$. D A representative example of CPDs of cells from one donor. 1,25D3 cultured cells exhibited lower CPDs compared to control hMSC ${ }^{* *}, \mathrm{p}<0.01$, student's t-test). E The time required to reach subconfluence was determined. 1,25D3 treated cells (gray bars) needed more days until they reached subconfluence compared to control hMSC (black bars) $(* *, p<0.01$, student's t-test). Independent experiments were performed using hMSC from several human donors. Control: P1, P2, P3, P4, $n=6$; P5, $n=5 ;$ P6, $n=3$. 1, 25D3: P1, P2, P3, $n=6$; P4, $\mathrm{n}=5 ; \mathrm{P} 5, \mathrm{n}=4 ; \mathrm{P} 6, \mathrm{n}=1$.

doi:10.1371/journal.pone.0029959.g002 
higher but without any significance compared to 1,25D3 treated cells. The CPDs of hMSG from several different donors (as indicated in the legend) were analyzed for up to six passages (Fig. 2C). Figure 2D shows growth curves and their respective CPDs for one donor. 1,25D3 treated hMSC displayed significantly lower CPDs compared to control cells (**, p<0.01). Although there was a donor-related variability of the proliferation rate, 1,25D3 stimulation caused an obvious growth retardation and $1,25 \mathrm{D} 3$ stimulated cells needed significantly more days until they reached subconfluence (**, $\mathrm{p}<0.01$ ) (Fig. 2E). The results are shown as mean from several donors (see figure legend for more information) and were consistent in all investigated donors.

\section{Morphological characteristics of 1,25D3 cultured hMSC}

1,25D3 treatment induced obvious morphological changes in hMSC. Cells lost their typical fibroblast-like features, enlarged their original cell volume and developed broadened and extended shapes compared to untreated hMSC. No signs of spontaneous differentiation, e.g. towards the development of lipid droplets or mineralization induction could be observed (Fig. 3A).

\section{Retransformation of $1,25 \mathrm{D} 3$ stimulated hMSC}

These 1,25D3 induced morphological changes in hMSG are partially reversible. After 1,25D3 treatment of hMSC over three passages cells were put back to normal medium (retransformed cells; r.c.). After two weeks the morphological changes were partially rescued (Fig. S3A). Some cells retained their 1,25D3 induced enlarged phenotype, some cells got their typical fibroblast-like features back. The cell number of control cells was nonsignificantly higher (average of three donors: cell number $=1.6 \times 10^{5}$ ) compared to the cell number of $1,25 \mathrm{D} 3$ treated cells (average of three donors: cell number $\left.=0.8 \times 10^{5}\right)$ at the same passages $($ Fig. S3B/C). The results are shown for three donors and the observed phenomena were consistent over all analyzed hMSC donors.

\section{Senescence-associated ß-galactosidase in 1,25D3 stimulated hMSC}

The impact of 1,25D3 on cellular senescence was determined by senescence-associated B-galactosidase staining in stimulated and unstimulated hMSC. Three different donors were cultivated with and without 1,25D3 for up to three passages. In stimulated hMSC (gray bar) a significant reduction of $\beta$-galactosidase staining was observed compared to unstimulated cells (black bar) $(p<0.001)$ (Fig. 3B). Furthermore we were able to follow up one donor for nine passages and compared 1,25D3 treated cells to control cells of P9. The significant effect, which was obvious at P3, was even more impressive in this late passage. 40 percent reduction of senescent hMSG could be counted $(\mathrm{p}<0.01)$ (data not shown).

\section{ROS accumulation in 1,25D3 treated hMSC}

The accumulation of ROS in 1,25D3 supplemented cells compared to untreated hMSG after $\mathrm{P} 1$ and $\mathrm{P} 3$ was measured by flow cytometry. As shown in Fig. S5A, a slight and nonsignificant reduction of oxidative stress induction after treating hMSC for one passage with 1,25D3 was observed. As depicted in Fig. S5B, $1,25 \mathrm{D} 3$ treatment of hMSC for a period of three passages led to a significant increase in ROS formation $(*, p<0.05)$.

\section{Effects of 1,25D3 treatment on the trilineage differentiation capacity of hMSC}

The maintenance of the multilineage capacity of $1,25 \mathrm{D} 3$ treated hMSC could be determined by subsequent chondrogenic, adipogenic and osteogenic differentiation in comparison to untreated controls. The induction of chondrogenesis, determined by Alcian blue staining of proteoglycans (Fig. 4A, upper panel), was quantified on digital images taken from chondrogenic pellets. $1,25 \mathrm{D} 3$ pretreatment increased the chondrogenic capacity of hMSC compared to cells grown without 1,25D3 supplementation,
A

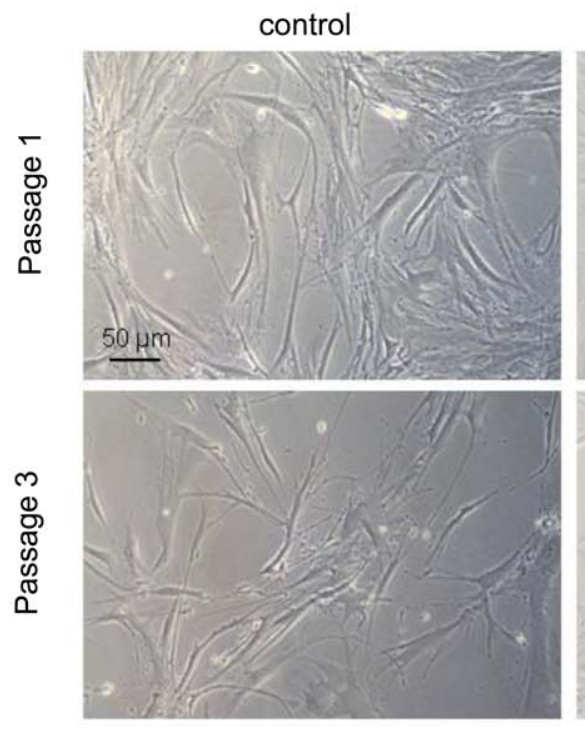

B
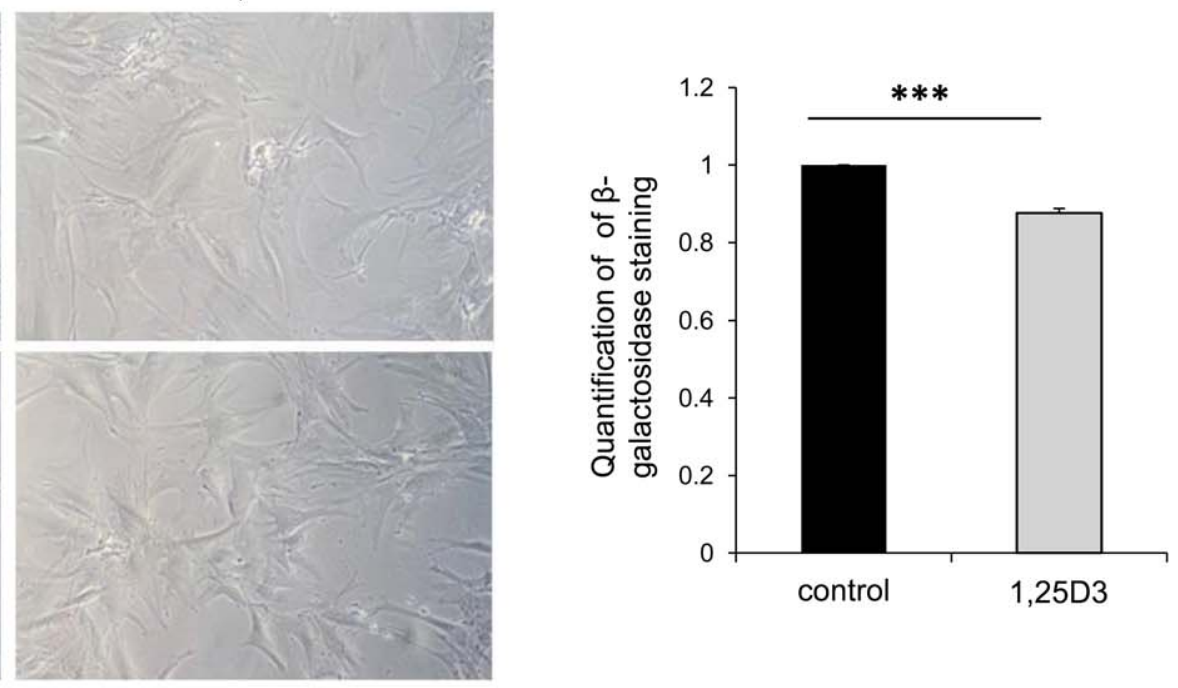

Figure 3. Morphological characteristics of 1,25D3 cultured hMSC and B-galactosidase quantification. A Morphology of hMSC in P1 (upper row) and P3 (lower row) treated with 1,25D3 over three passages compared to control cells. 1,25D3 incubated hMSC lost their typical fibroblast-like features and showed a broadened and extended cellular morphology. Scale bar $=50 \mu \mathrm{m}$. B The induction of B-galactosidase was significantly reduced in 1,25D3 cultured cells compared to control hMSC. Cells from three different donors were used and were cultured up to three passages. The results are shown as mean+SEM of three independent experiments, each normalized to its control. Each time five pictures of $\beta$ galactosidase staining were analyzed using the AutMess tool of AxioVision Rel. 4.6 software. (***, $p<0.001$, student's t-test). doi:10.1371/journal.pone.0029959.g003 

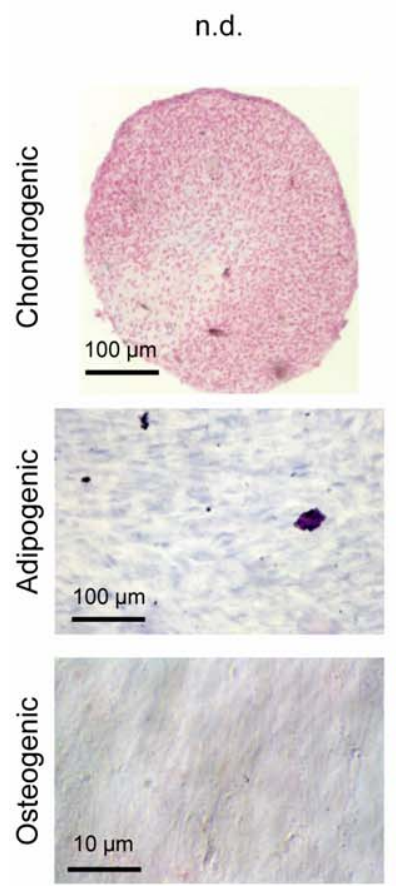
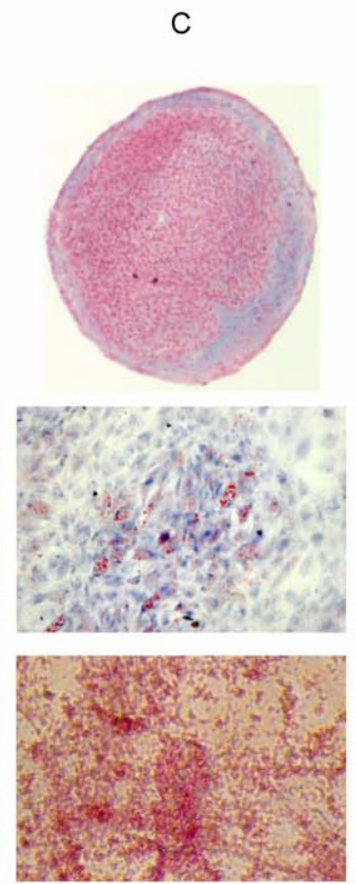

B
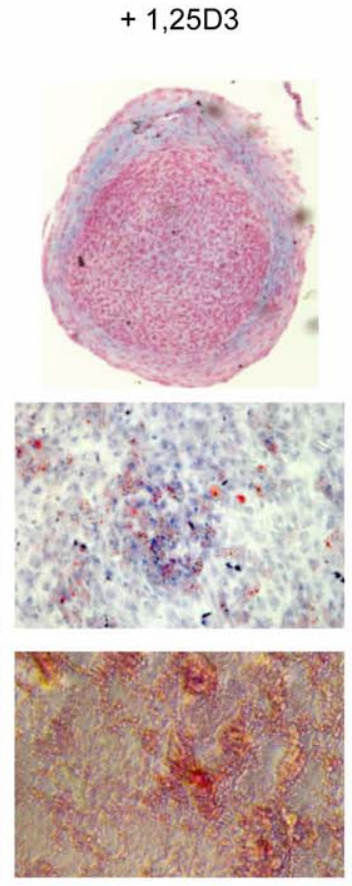

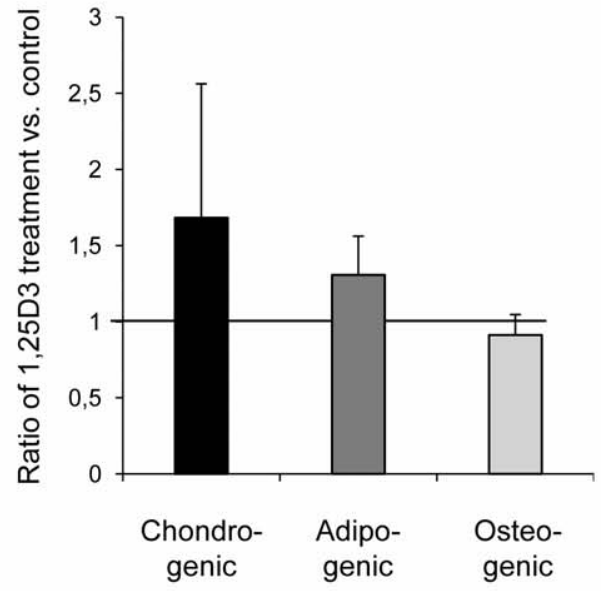

Figure 4. Trilineage differentiation capacity of 1,25D3 pretreated hMSC. A Chondrogenic, adipogenic and osteogenic differentiation of hMSC after 1,25D3 pretreatment over three passages. Alcian Blue staining of chondrogenic differentiated hMSC (upper panel), Oil Red O staining for intracellular lipid vesicles during adipogenic differentiation (middle panel) and Alizarin Red $\mathrm{S}$ staining of mineralized extracellular matrix after osteogenic differentiation (lower panel) are shown (n.d. $=$ not differentiated; $C=$ differentiated control; $+1,25 D 3=$ differentiated, cells pretreated for three passages with 1,25D3). The figure is representative for three independent experiments. The bar represents $100 \mu \mathrm{m}$ and $10 \mu \mathrm{m}$, respectively as indicated. B Quantification of chondrogenic (black bar), adipogenic (dark gray bar) and osteogenic differentiation (light gray bar) after three passages $1,25 \mathrm{D} 3$ pretreatment in comparison to untreated cells. For each differentiation lineage the Fold Change was calculated by comparing the induction of differentiation of 1,25D3 pretreated cells with control cells. The results are shown as means of three independent experiments+SEM using three different preparations of hMSC. Each time 5 to 9 pictures of each differentiation experiment were analyzed using the AutMess tool of the software of AxioVision Rel. 4.6.

doi:10.1371/journal.pone.0029959.g004

although values were not significant (Fig. 4B). Variability between the donors was observed. Two donors displayed almost the same chondrogenic induction between untreated differentiated cells and 1,25D3 pretreated hMSC, whereas one donor showed a strong enhanced induction of chondrogenesis after 1,25D3 pretreatment.

We also determined the adipogenic capacity of 1,25D3 pretreated cells versus untreated control hMSC. After adipogenic induction, oil droplet formation was found to a lesser extent in control hMSC than in 1,25D3 pretreated cells (Fig. 4A, middle panel). This difference was not statistically significant (Fig. 4B).

After two weeks under osteogenic conditions, 1,25D3 pretreated hMSC showed a slightly enhanced ALP staining compared to untreated cells (Fig. S4A, upper panel and B). This effect was reversed after four weeks of osteogenic culturing (Fig. S4A, lower panel and B), where both 1,25D3 pretreated and untreated hMSC displayed an almost equivalent amount of mineralization shown by Alizarin Red O staining (Fig. 4A, lower panel and B).

\section{Effects of $1,25 \mathrm{D} 3$ treatment on the expression of quiescence markers}

To investigate if $1,25 \mathrm{D} 3$ treatment over three passages had an impact on cellular quiescence, we analyzed the expression level of selected quiescence-associated genes. The gene expression of forkhead box O1 (FOXO1a) displayed a fold change of 1.5, forkhead box $\mathrm{O} 3(\mathrm{FOXO3a})$ was 1.2-fold up-regulated and forkhead box O4 (FOXO4) was 1.7-fold up-regulated in 1,25D3 stimulated hMSC at P3 compared to control cells. Nanog homeobox $(\mathcal{N} A N O G)$ is slightly induced by $1,25 \mathrm{D} 3$ treatment and revealed a fold change of 1.3. Thioredoxin interacting protein $\left(T_{x} N I P\right)$ was induced in $1,25 \mathrm{D} 3$ treated cells and was 1.6 -fold upregulated. Tumor protein p53 (TP53) showed a 1.9-fold upregulation due to 1,25D3 treatment (Fig. 5A).

\section{Effects of 1,25D3 treatment on the expression of senescence markers}

The gene expression of the senescence-associated genes cyclindependent kinase inhibitor 2B (P15), cyclin-dependent kinase inhibitor 2A (P16), cyclin-dependent kinase inhibitor 1A (P21) and proteasome 26S subunit, non-ATPase, 9 (P27) in hMSC cultured with or without $1,25 \mathrm{D} 3$ for four passages led to a significant 0.4 -fold $(\mathrm{p}<0.05)$ downregulation of P16 gene expression and to a nonsignificant 1.6-fold upregulation of $P 15$ expression compared to control cells. 1,25D3 treatment had no effect on $P 27$ expression and $P 21$ expression was only marginally induced (fold change $=1.2$ ). Long-term stimulation of hMSG (P4) had also no significant effects on mRNA expression of the senescence-associated pregnancy specific beta-glycoproteins $P S G \mathrm{~s}$. We focused our analyses on PSG1 and PSG5 and could demonstrate that the gene expression of PSG1 was slightly 0.8-fold downregulated in 1,25D3 treated cells in $\mathrm{P} 4$ while the expression of PSG5 was unchanged (Fig. 5B). 


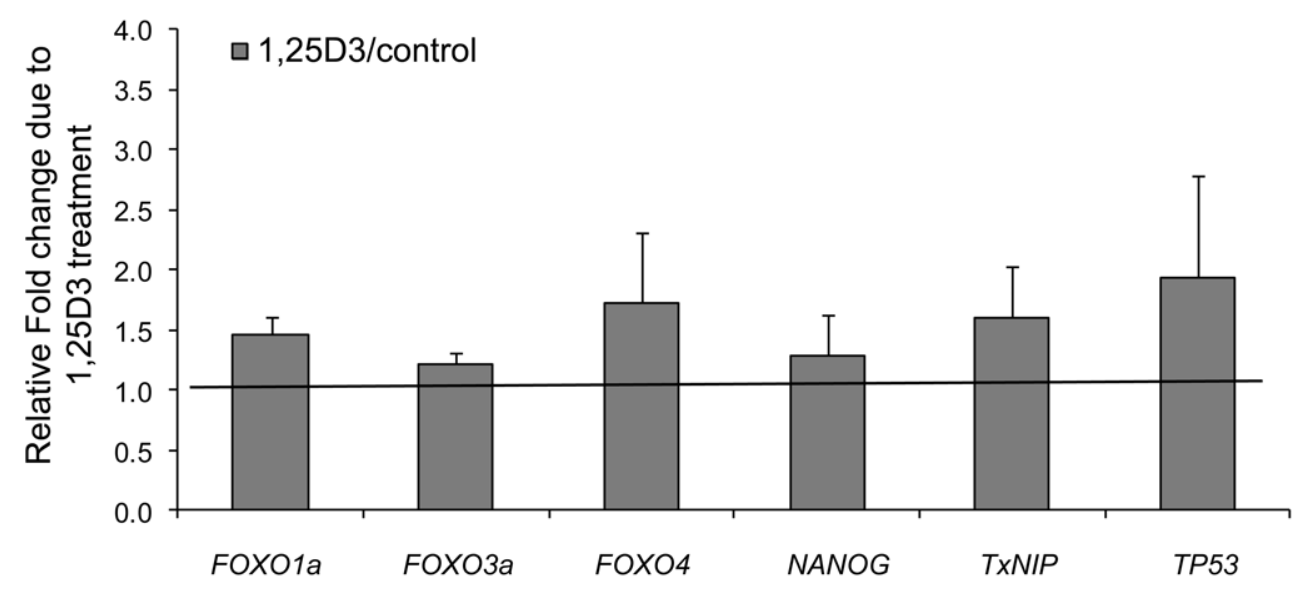

B

\section{SENESCENCE MARKERS}

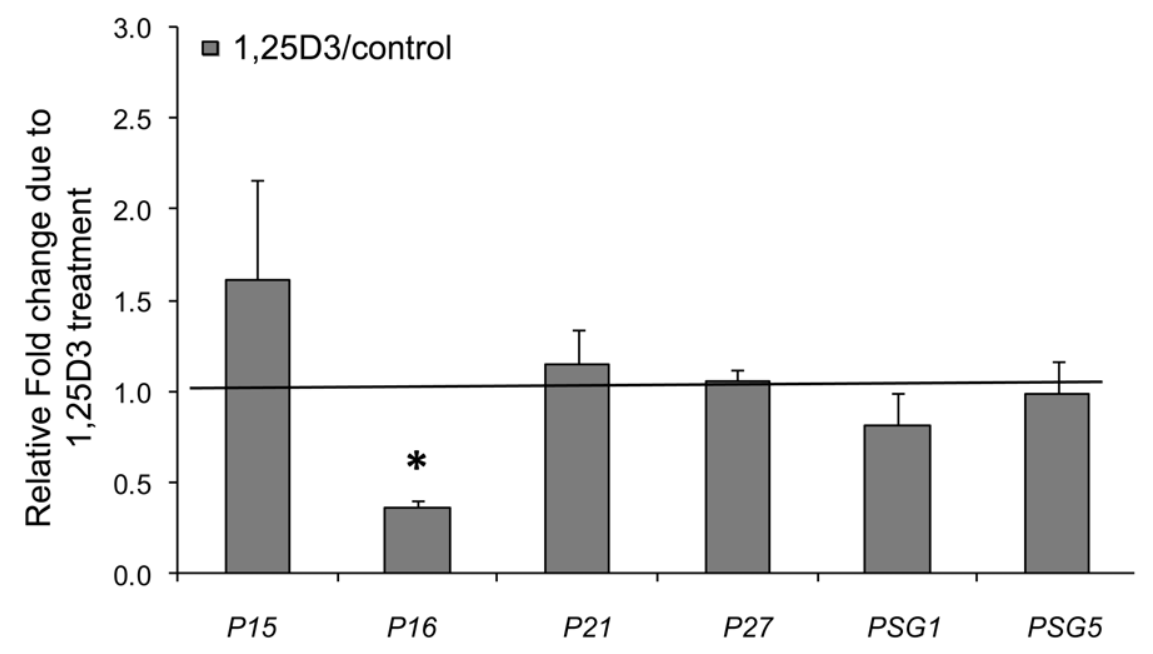

Figure 5. Effects of 1,25D3 treatment on quiescence- and senescence-associated genes. A Expression of quiescence markers and densitometric quantification of semiquantitative RT-PCR results of hMSC (P3) treated with or without 1,25D3. Cells from five different donors were used. For each donor the Fold Change was calculated by comparing the expression of 1,25D3 treated cells with control cells. The results are shown as mean+SEM. The gene expression levels of FOXO1a, FOXO3a, FOXO4, NANOG, TXNIP, TP53 were induced by 1,25D3 treatment over 3 passages. (FOXO1a: forkhead box 1a, FOXO3a: forkhead box 3a, FOXO4: forkhead box 4, NANOG: Nanog homeobox, TxNIP: thioredoxin interacting protein, TP53: tumor protein p53). B Expression of senescence markers and densitometric quantification of semiquantitative RT-PCR results of hMSC treated with or without $1,25 \mathrm{D} 3$ over at least four passages. 1,25D3 treatment reduced $P 16$ expression $(p<0.05)$ and induced $P 15$ expression in cells at P4 compared to control cells. $P 27$ and $P 21$ gene expression in P4 showed no $(P 27)$ or only very weak $(P 21)$ induction by $1,25 \mathrm{D} 3$ treatment. Densitometric quantification of the semi-quantitative PCR results revealed downregulation of PSG1 and almost no change in the expression of PSG5 at P4 in 1,25D3 stimulated hMSC. The Relative Fold change represents the factor of different gene expression levels in 1,25D3 treated hMSC versus control cells. Expression profile of senescence-associated genes was determined in P4. Cells from three different donors were used. For each donor the Fold Change was calculated by comparing the expression of $1,25 \mathrm{D} 3$ treated cells with control cells. The results are shown as mean+SEM. ${ }^{*}, \mathrm{p}<0.05$, student's t-test).

doi:10.1371/journal.pone.0029959.g005

\section{Discussion}

Based on the knowledge of aging-promoting properties of unbalanced systemic 1,25D 3 excess in animal models we analyzed cellular 1,25D3 effects on hMSG by cell proliferation and apoptosis assay, $\beta$-galactosidase staining, VDR and surface marker immunocytochemistry and RT-PCR of 1,25D3-responsive, quiescence- and replicative senescence-associated genes.

In order to validate the response of hMSC to $1,25 \mathrm{D} 3$ treatment, we first showed that $1,25 \mathrm{D} 3$ short-term stimulation modulates the responsive genes CYP24A1, $O C$ and $O P \mathcal{N}$ in hMSC. Additionally, nuclear translocation of the liganded VDR receptor could be confirmed by immunostaining.

To characterize hMSC, which were stimulated with 1,25D3 for three or more passages, we investigated surface marker analysis, clonogenic capacity and cell morphology. The analysis of the surface marker expression of 1,25D3 stimulated hMSC did not change with respect to mesenchymal markers $\left(\mathrm{CD} 73^{+}, \mathrm{CD} 90^{+}\right.$, $\mathrm{CD} 105^{+}$) and hematopoetic markers $\left(\mathrm{CD} 34^{-}, \mathrm{CD} 45^{-}\right.$, HLA$\mathrm{DR}^{-}$) as analyzed by FACS in comparison to untreated cells. Moreover there was no loss of clonogenic capacity in $1,25 \mathrm{D} 3$ treated hMSC. 1,25D3 treated hMSC lost their typical fibroblast- 
like features, enlarged their original cell volume and developed broadened and extended shapes compared to untreated hMSG. When 1,25D3 was withdrawn in long term cultures the morphology only partially returned to the fibroblast like appearance.

In short-term time response experiments, stimulation of hMSC with 1,25D3 showed the strongest inhibitory effect on hMSC proliferation and apoptosis after $72 \mathrm{~h}$. This might directly result from the interaction of $1,25 \mathrm{D} 3$ with its nuclear receptor $\mathrm{nVDR}$ and the modulation of gene transcription. Otherwise secondary effects could also be involved since 1,25D 3 responsive genes might regulate downstream effects. The effect on hMSC however is different with respect to lineage commitment from e.g. that on promyelocytes where 1,25D3 induces monocytic differentiation together with inhibition of proliferation [20].

Numerous in vitro and in vivo studies have demonstrated that 1,25D3 inhibits proliferation of a wide range of cell types. In smooth muscle cells 1,25D3 inhibits endothelin-induced proliferation [21-22] and Gonzalez-Pardo et al. [23] mentioned the antiproliferative effects of 1,25D3 and the 1,25D3-analog TX527 on the growth of endothelial cells in vitro and in vivo. Our results demonstrate the ability of $1,25 \mathrm{D} 3$ to inhibit proliferation rate in hMSC compared to control cells. Human MSC grown under permanent 1,25D3 treatment for up to six passages showed lower CPDs compared to control cells and needed significantly more days until they reached subconfluence, suggesting that vitamin D signaling leads to a deceleration of proliferative processes, accompanied by changes of cell morphology and a delay of replicative senescence.

This could be confirmed by staining and quantification of $\beta$ galactosidase, an accepted marker for cellular senescence [24], in 1,25D3 treated hMSC compared to control cells. The number of positive cells from $\mathrm{P} 3$ in three donors after staining for senescenceassociated $\beta$-galactosidase was compared. The amount of $\beta-$ galactosidase staining in 1,25D3 stimulated cells was significantly lower compared to control hMSC. Although the determination of ROS accumulation in 1,25D3 supplemented cells was significantly enhanced compared to control cells (P3) 1,25D3 stimulation had no impact on the induction of senescence in hMSC.

Although 1,25D3 is not capable of inducing robust commitment and differentiation towards the chondrogenic, adipogenic and osteogenic pathway, the stimulatory effect in the gut on calcium and phosphate absorption is generally well accepted as a proosteogenic and pro-mineralization effector. We determined the multilineage capacity of $1,25 \mathrm{D} 3$ pretreated cells compared to untreated control hMSC. There was no difference with respect to their capacity to differentiate towards one of these pathways. Moreover, there was even a tendency, although not significant, towards enhanced chondrogenic and adipogenic differentiation. It has been reported earlier that 1,25D3 stimulates chondrogenic differentiation via the membrane-associated MARRS-receptor by modulating IGF-1 production, which would be in line with our results [25]. We conclude from these results that long-term 1,25D3 treatment in vitro did not per se induce chondrogenic, adipogenic or osteogenic commitment and that hMSG maintain their multipotency even after long-term stimulation with 1,25D3.

The effect of reduced proliferation and changes in cell morphology raised the question regarding the biology of the resulting population. To find evidence for quiescence we analyzed the expression of known quiescence markers [26] as FOXO mRNAs and also $N A N O G$, TxNIP and TP53. The forkhead box $\mathrm{O}$ (FOXO) proteins are activated in response to oxidative stress and up-regulate genes involved in ROS detoxification and cell-cycle arrest [27-28]. In five donors permanent 1,25D3 treatment leads to a modest up-regulation of FOXO1a, FOXO3a and FOXO4. Pierantozzi [29] could show that in hMSG Nanog homeobox $(\mathcal{N} A N O G)$ expression is associated with quiescence and our data demonstrate a weak induction of $\mathcal{N A N O G}$ expression in $1,25 \mathrm{D} 3$ stimulated cells in all donors. Furthermore the Thioredoxin interacting protein $\left(T_{x} N I P\right)$, a regulator of hematopoietic stem cell (HSC) quiescence under stress conditions [30], was induced in 1,25D3 treated cells. Finally also the tumor protein TP53 (P53), which has an important role in the cellular response to DNA damage and plays also a critical role in regulating HSC [31], is upregulated by $1,25 \mathrm{D} 3$. In summary we see a trend toward an enhanced expression of genes associated with cellular quiescence. This interpretation may also be fostered by the fact that $1,25 \mathrm{D} 3$ treatment attenuates cumulative population doublings without inducing senescence.

To follow up the impact of permanent 1,25D3 stimulation in hMSC we also analyzed the expression of selected genes associated with senescence. This analysis of senescence-associated genes like the cyclin-dependent kinase inhibitors 2B (P15), 2A (P16), 1A (P21) and the proteasome 26S subunit, non-ATPase, 9 (P27), which regulate the cell cycle of eukaryotic cells [32] surprisingly revealed a significant reduction of $P 16$ expression in permanently 1,25D3 stimulated cells. The senescence associated genes P15, P21 and $P 27$ were not significantly affected in comparison to unstimulated controls. Furthermore also the pregnancy specific beta-glycoproteins (PSG1, PSG5), which are known to be markedly up-regulated during replicative senescence [33] were not induced by 1,25D3. Hence we have no evidence for an enhanced expression of senescence-associated genes in 1,25D3 stimulated MSC, but substantial evidence for the opposite effect.

In conclusion our data suggest that 1,25D3 does not induce premature aging phenomena or cellular senescence in hMSC. Our data are very much in line with the recently published phenotype of premature aging in $V D R^{-/-}$mice. Besides the fact that vitamin D3 supplementation have been given to humans for at least 40 years without significant health problems our results are especially reassuring since is established as a basic therapy in osteoporosis prevention and treatment and is presently being discussed as a means of cancer prevention [34]. The preponderance of evidence from all readouts indicates that 1,25D3 does not promote aging in this important cell population for mesenchymal tissue regeneration but in contrast delays senescence development.

\section{Materials and Methods}

\section{Chemicals}

Chemicals were obtained from AppliChem GmbH (Darmstadt, Germany), Applied Biosystems Deutschland GmbH (Darmstadt, Germany), Invitrogen GmbH (Karlsruhe, Germany), Carl Roth GmbH (Karlsruhe, Germany), R\&D Systems GmbH (Wiesbaden, Germany), Sigma-Aldrich GmbH (Schnelldorf, Germany) and GE Healthcare Europe GmbH (Freiburg, Germany) in p. A. quality. 1,25D3 was obtained from Sigma-Aldrich GmbH (Schnelldorf, Germany).

All experiments were performed using $1,25 \mathrm{D} 3$ in a concentration of $100 \mathrm{nM}$.

\section{Isolation and culture of hMSC}

Media for cell culture and fetal bovine serum were purchased from PAA Laboratories GmbH (Linz, Austria).

Primary hMSC were isolated from femoral heads due to hip replacement therapies from 11 different donors and cultured as described [35-36]. Cells were plated for stimulation experiments in P1 with or without $100 \mathrm{nM} \mathrm{1,25D3}$ at a density of 5000 cells 
per $\mathrm{cm}^{2}$ and were cultivated until $80 \%-90 \%$ confluence at $37^{\circ} \mathrm{C}$ in $5 \% \mathrm{CO}_{2}$ in expansion medium (DMEM Ham's F12 supplemented with $10 \%$ FCS, $1 \mathrm{U} / \mathrm{ml}$ penicillin, $100 \mu \mathrm{g} / \mathrm{ml}$ streptomycin and $50 \mu \mathrm{g} / \mathrm{ml}$ ascorbate). Experiments were performed upon approval by the Local Ethics Committee of the University of Würzburg and informed consent from each patient.

\section{Isolation of RNA and RT-PCR}

Total RNA was isolated using the NucleoSpin ${ }^{\circledR}$ RNAII kit (Macherey-Nagel GmbH, Düren, Germany) according to the manufacturer's instructions. RNA was obtained from hMSC cultivated for $24 \mathrm{~h}$ with $100 \mathrm{nM} 1,25 \mathrm{D} 3$.

Two micrograms of total RNA were reverse-transcribed with MMLV reverse transcriptase (Promega GmbH, Mannheim, Germany) in a volume of $25 \mu \mathrm{l}$. For amplification of selected genes $1 \mu \mathrm{l}$ of cDNA was used as a template in a volume of $50 \mu \mathrm{l}$. The mixture contained $10 \times$ Reaction Buffer, $20 \mathrm{mM}$ each of four dNTPs, 25 pmol each of primer and 1.25 U of Taq DNA Polymerase (Peqlab GmbH, Erlangen, Germany). RT-PGR conditions were as follows: $30 \mathrm{sec}$ at $94 \mathrm{C}, 30 \mathrm{sec}$ at annealing temperature, $30 \mathrm{sec}$ at $72 \mathrm{C}$. The used primer-sequences, annealing temperatures, $\mathrm{MgCl}_{2}$ concentrations, and the size of the PCR products are listed in Table 1. Transcript amounts were evaluated by gel electrophoresis and quantified by densitometry analysis as described previously [37] using the LTF Bio 1D software (LTF, Wasserburg, Germany). Values were obtained from three to five independent experiments and were normalized to EF $1 \alpha$ transcripts serving as a reference. Afterwards mRNA amounts of analyzed genes were normalized on mRNA quantities of corresponding control. Then for each donor the Fold Change was calculated by comparing the expression of 1,25D3 treated cells with control cells. The results are shown as mean+SEM.

\section{VDR immunocytochemistry}

Human MSC were grown on coverslips in sixwell-plates for three days and then stimulated with $100 \mathrm{nM} 1,25 \mathrm{D} 3$ for $24 \mathrm{~h}$. Afterwards cells were washed thrice with PBS (pH 7.2), fixed with icecold $\mathrm{MetOH}(5 \mathrm{~min})$, dried and stored at $-80 \mathrm{C}$ until staining. Before and after permeabilization with PBS $-0.05 \%$ Tween-20, cells were washed thrice with PBS, and then blocked with $3 \%$ BSA in PBS. The coverslips were incubated with the primary antibody VDR (C-20), 1:100, (sc-1008, Santa Cruz Biotechnology, Inc., Heidelberg, Germany) for $16 \mathrm{~h}$ at $4^{\circ} \mathrm{C}$ and a phycoerythrinlabeled secondary antibody, NorthernLights Anti-rabbit IgGNL557, 1:400, (NL004, R\&D Systems GmbH, WiesbadenNordenstadt, Germany) for $2 \mathrm{~h}$ at RT. Finally the coverslips were applied to a drop of Vectashield with DAPI (LINARIS GmbH, Wertheim, Germany) on slides and observed under a fluorescence microscope (Axioskop2, filters 1 and 20, Carl Zeiss MicroImaging $\mathrm{GmbH}$, Göttingen, Germany). Pictures were taken from three independent donors, one representative experiment is shown.

\section{Immunophenotyping of 1,25D3 treated hMSC: Flow cytometry}

Human MSC, cultivated with or without 1,25D3 over 3 passages, were trypsinized, washed and resuspended in PBS plus $1 \%$ BSA after P1 and P3. The cells were then labeled with fluorescein isothiocyanate (FITC)- and phycoerythrin (PE)-conjugated monoclonal antibodies. The antibodies used were: CD105PE, CD90-PE, CD73-PE (mesenchymal markers), HLA-DRFITC (AbD Serotec, Düsseldorf, Germany) CD34-FITC, CD45FITC (hematopoietic markers) (BD Biosciences, Heidelberg,
Germany). Mouse isotype antibodies served as controls (BD Biosciences, Heidelberg, Germany). Then hMSG were washed twice with PBS plus 1\% BSA. For fluorescence activated cell sorting analysis (FACS) labeled cells were resuspended in PBS plus $1 \%$ BSA at a concentration of $8 \times 10^{5} \mathrm{cells} / \mathrm{ml}$. Flow cytometry analysis (10000 events) was performed using a BD LSR II (Becton Dickinson, Heidelberg, Germany). Figures were generated using FlowJo software. Analyses were performed by using three independent donors.

\section{Colony Forming Unit (CFU) Assay}

1,25D3 treated hMSG and control hMSG at Pl and P3 respectively were cultured in Petri dishes. The medium was totally renewed every 3-4 days. Fifteen days after standardized seeding at 800 cells per Petri dish $\left(14\right.$ cells per $\left.\mathrm{cm}^{2}\right)$, cells were washed 2 times with PBS, fixed with methanol, and stained with $0.5 \%$ Crystal Violet. Cell clusters of more than 25 cells were counted as CFU originating from one clonal cell. The CFUs were scored using AxioVision Rel. 4.6 (Carl Zeiss MicroImaging GmbH, Göttingen, Germany). Experiments were performed in three to five independent donors.

\section{Cell proliferation and apoptosis assay}

For determination of 1,25D3 short-term effects on proliferation and apoptosis, hMSG ( $\mathrm{P} 1$ or 2, respectively) were seeded on 96 well plates (1000 cells/well). $24 \mathrm{~h}$ after seeding hMSC were stimulated with $100 \mathrm{nM}$ 1,25D3 for 24, 48 and $72 \mathrm{~h}$. Proliferation and apoptosis rates of treated hMSC compared to non-treated hMSC were quantified by Caspase-Glo ${ }^{\circledR} 3 / 7$ Assay and CellTiterGlo ${ }^{\circledR}$ 3/7 Luminescent Cell Viability Assay (both Promega $\mathrm{GmbH}$, Mannheim, Germany) according to the manufacturer's instructions. Luminescence was measured with an Orion II Luminometer (Berthold Detection Systems, Pforzheim, Germany). Proliferation and apoptosis experiments were performed by using hMSC of 3 human donors. Averages were calculated from 3 different measuring points and 3 independent hMSC preparations.

\section{Growth rate analysis}

Passage 0 hMSC were trypsinized and reseeded in culture media with or without $100 \mathrm{nM}$ 1,25D3 at a density of 5000 cells per $\mathrm{cm}^{2}$. These hMSC were allowed to grow until they reached 80\%-90\% confluence and then passaged at the same cell density onwards up to P6. As the cell number of hMSC could be determined for the first time at $\mathrm{P} 1$, the cumulative population doubling (CPD) was first determined for P2. CPDs were calculated as described previously [38-39].

\section{Retransformation of $1,25 \mathrm{D} 3$ treated hMSC}

After three passages of 1,25D3 supplementation, half of these hMSC were cultivated 1,25D3-deprived, whereas the other half was still stimulated. 200 cells per $\mathrm{cm}^{2}$ were seeded and after a growth period of two weeks the cell number of 1,25D3 treated and 1,25D3 untreated hMSC was determined.

\section{Senescence-associated ß-galactosidase staining and determination of $ß$-galactosidase positive cells}

For detection of senescent cells senescence-associated Bgalactosidase staining (counterstain: Nuclear fast red, Merck KGaA, Darmstadt; Germany) was performed as described [24] Cells were observed under the microscope for positive blue stained cytoplasm. Each time five pictures of $B$-galactosidase staining of three independent donors were quantified using the AutMess tool of AxioVision Rel. 4.6 software. 
Table 1. Primers used for RT-PCR experiments.

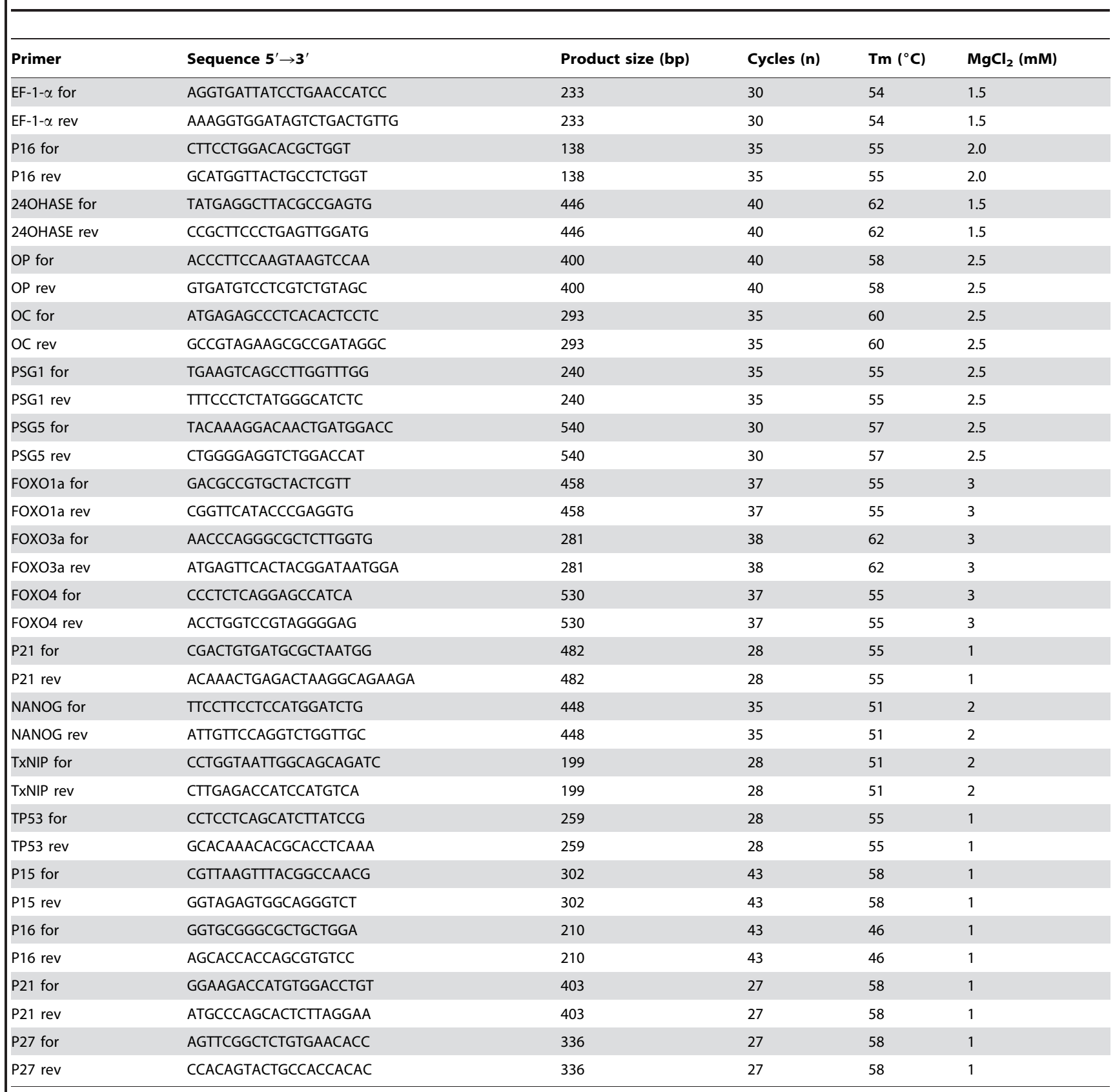

Primer sequences, fragment lengths and PCR conditions including number of cycles, annealing temperature and magnesium supplementation.

doi:10.1371/journal.pone.0029959.t001

Flow cytometric analysis of oxidative stress

In first-passage and third-passage hMSC cultivated with or without 1,25D3, the accumulation of reactive oxygen species (ROS) was determined using $2^{\prime} 7^{\prime}$-dichlorofluorescin diacetate $\left(\mathrm{H}_{2} \mathrm{DCF}-\mathrm{DA}\right)$. Intracellular ROS, e.g. hydrogen peroxide, oxidize nonfluorescent $\mathrm{H}_{2} \mathrm{DCF}-\mathrm{DA}$ to fluorescent dichlorofluorescin (DCF) [40-41]. Cells were incubated with $30 \mu \mathrm{M} \mathrm{H} \mathrm{H}_{2}$ DCF-DA for $45 \mathrm{~min}$, trypsinized, and washed three times with PBS plus $1 \%$ BSA. The rate of oxidation was analyzed $\left(3 \times 10^{5}\right.$ cells/sample) by flow cytometry using a BD LSR I (Becton Dickinson, Heidelberg, Germany) after incubation for $10 \mathrm{~min}$ on ice with $1 \mu \mathrm{g} / \mathrm{ml}$ propidium iodide, as described by Schupp et al. [42]. The obtained data were evaluated with the CellQuest Pro software, by defining a region within the DCF-propidium iodide dot blot containing $2 \times 10^{3}$ propidium iodide-negative cells. The mean value of this population was determined and used for the statistical analysis. Data were obtained from three independent experiments.

\section{In Vitro Differentiation}

Human MSC cultivated with and without 100 nM 1,25D3 for 3 passages were used for differentiation experiments. Differentiation experiments were started in P3 when cells had reached confluence. Human MSG were incubated in expansion medium (negative control) or in cell differentiation medium. 
Ghondrogenic Differentiation. For chondrogenic differentiation hMSC were cultured as high-density pellet cultures. Therefore $2.5 \times 10^{5}$ cells were resuspended in chondrogenic differentiation medium (DMEM high glucose supplemented with $50 \mu \mathrm{g} / \mathrm{ml}$ ascorbate-2-phosphate, $100 \mathrm{nM}$ dexamethasone, $100 \mu \mathrm{g} / \mathrm{ml}$ pyruvate, $40 \mu \mathrm{g} / \mathrm{ml}$ proline, $1 \%$ ITS $+1,1 \mathrm{U} / \mathrm{ml}$ penicillin, $100 \mu \mathrm{g} / \mathrm{ml}$ streptomycin and $10 \mathrm{ng} /$ $\mathrm{ml}$ TGF- $\beta$-1, with and without the addition of $100 \mathrm{nM} 1,25 \mathrm{D} 3$ ), centrifuged in a $15 \mathrm{ml}$ polypropylene tube (Greiner Bio-One $\mathrm{GmbH}$, Frickenhausen, Germany) at $250 \mathrm{~g}$ to form a pellet, and cultured for three weeks as described previously [35]. Pellets cultured in chondrogenic differentiation medium without the addition of TGF- $\beta$ - 1 served as negative controls. Chondrogenic high-density pellet cultures were fixed in $4 \%$ paraformaldehyde, dehydrated through a graded ethanol series and embedded in paraffin. Sections of $4 \mu \mathrm{m}$ were stained with $1 \%$ Alcian Blue (pH 1.0) for sulfated proteoglycans and counterstained with Nuclear Fast Red. Cells cultured in expansion medium served as negative control.

Adipogenic Differentiation. For adipogenic differentiation hMSC were seeded at a density of $2.1 \times 10^{4}$ cells per $\mathrm{cm}^{2}$, cultivated until confluence and incubated in adipogenic differentiation medium consisting of DMEM high glucose, $10 \%$ FCS, $1 \mathrm{U} / \mathrm{ml}$ penicillin, $100 \mu \mathrm{g} / \mathrm{ml}$ streptomycin, $1 \mu \mathrm{M}$ dexamethasone, $0.5 \mathrm{mM}$ 3-isobutyl-1-methylxanthine (IBMX), $1 \mu \mathrm{g} / \mathrm{ml}$ insulin and $100 \mu \mathrm{M}$ indomethacin. At day 14 intracellular lipid vesicles of adipogenic monolayer cultures were stained with Oil Red O solution (Merck, Darmstadt, Germany) [43]. During the adipogenic differentiation process, no 1,25D3 was applied. Cells cultured in expansion expansion medium served as negative control.

Osteogenic Differentiation. For osteogenic differentiation cells were seeded at a density of $2.1 \times 10^{4}$ cells per $\mathrm{cm}^{2}$ and grown until confluence. Osteogenic differentiation of confluent monolayer cultures was then induced with osteogenic differentiation medium (DMEM high glucose supplemented with $10 \%$ FCS, $50 \mu \mathrm{g} / \mathrm{ml}$ ascorbate, $10 \mathrm{mM} \beta$-glycerophosphate, $1 \mathrm{U} / \mathrm{ml}$ penicillin, $100 \mu \mathrm{g} / \mathrm{ml}$ streptomycin and $100 \mathrm{nM}$ dexamethasone) for four weeks. During the osteogenic differentiation process, no 1,25D3 was applied. Cells cultured in expansion expansion medium served as negative control. The mineralized extracellular matrix was determined by staining for calcium hydrogen phosphate using Alizarin Red S (ChromaGesellschaft Scnmid \& Co., Stuttgart, Germany) as described previously [44]. Cytoplasmic ALP was stained using the Alkaline Phosphatase, Leukocyte Kit 86-C (Sigma Aldrich GmbH, Munich, Germany) according to the manufacturer's instructions.

\section{Statistics}

The results are expressed as means+standard error (SEM). For comparison between two groups the student's t-test and the MannWhitney $\mathrm{U}$ test were performed as indicated.

\section{Supporting Information}

Figure S1 Immunophenotyping of 1,25D3 treated hMSC compared to untreated hMSG. 1,25D3 treated hMSG and untreated cells at passage 1 (A) and 3 (B) were analyzed with flow cytometry to detect the cell surface marker expression. Results are shown for one representative donor. Yellow peaks represent the specific antibody staining of control cells, blue peaks represent the specific antibody staining of 1,25D3 treated hMSC, and red peaks represent the isotype control antibody staining of 1,25D3 cultured cells (right panels). Histogram overlays show 1,25D3 treated
hMSC and control cells gated for CD73, CD90 and CD105 positivity. CD73, CD90 and CD105 expression of 1,25D3 treated cells and untreated hMSC was between $88.9 \%$ and $98.7 \%$. This was consistent over three separate experiments using hMSC from three donors (control $=1,25 \mathrm{D} 3$ untreated cells; 1,25D3 $=1,25 \mathrm{D} 3$ stimulated hMSC; IgG = isotype control).

(TIF)

Figure S2 Number of GFUs of 1,25D3 treated hMSG. After passage 1 and 3 the effect of 1,25D3 treatment on CFU number was evaluated in hMSC and compared to untreated hMSC. No significant difference was obtained in CFU number between 1,25D3 treated cells (gray bars) and control hMSC (black bars) at P1 and also at P3. Data show mean+SEM of three (P3) or five $(\mathrm{Pl})$ independent experiments, respectively.

(TIF)

Figure S3 Retransformation of 1,25D3 stimulated hMSC. A The 1,25D3 induced morphological changes are not completely reversible when 1,25D3 treated hMSC are again cultured in normal medium. Some cells retrained their 1,25D3 induced enlarged volume (r.c. = retransformed cells; $1,25 \mathrm{D} 3=1,25 \mathrm{D} 3$ treated $\mathrm{hMSC}$ ). The results are shown for one representative donor and observations were consistent over 3 independent experiments using hMSG from three donors. Scale bar $=50 \mu \mathrm{m}$. B The cell number of 1,25D3 treated and retransformed cells was determined. Data show mean+SEM of three independent experiments using cells from three donors. C The cell number of 1,25D3 treated and retransformed cells was determined. Therefore three donors were analyzed. Retransformed hMSC displayed an obvious higher cell number compared to $1,25 \mathrm{D} 3$ treated cells

(TIF)

Figure S4 Osteogenic differentiation capacity of 1,25D3 treated hMSG. A Staining for ALP after osteogenic differentiation for 14 days (upper row) and for 28 days (lower row). Staining for cytoplasmic ALP was performed for undifferentiated hMSC (n.d.) as well as for hMSC pretreated with and without 1,25D3 $(\mathrm{C}=$ differentiated control; $+1,25 \mathrm{D} 3=$ differentiated $1,25 \mathrm{D} 3$ pretreated cells). The figure is representative of three independent experiments. Scale bar $=50 \mu \mathrm{m}$. B Quantification of ALP staining after 1,25D3 pretreatment over 3 passages and 1,25D3 untreated hMSC over 3 passages as a result of two or four weeks of osteogenic differentiation. The Fold Change was calculated by comparing the induction of differentiation of 1,25D3 pretreated cells with control cells. After two weeks under osteogenic conditions, 1,25D3 pretreated hMSC showed a slightly enhanced ALP staining compared to untreated cells, and after four weeks under osteogenic conditions, 1,25D3 pretreated hMSG revealed significant reduced ALP staining compared to untreated hMSC (*; p $<0.05$, student's t-test). The results are shown as means of three independent experiments+SEM using different preparations of hMSG. Each time 6 pictures of ALP staining were analyzed using the AutMess tool of AxioVision Rel. 4.6 software.

(TIF)

Figure S5 Flow cytometric analysis of 1,25D3-induced ROS formation in hMSG after P1 and P3. Oxidative stress in cells cultured for one passage $(\mathbf{A})$ and for three passages $(\mathbf{B})$ with (gray bar) and without (black bar) 1,25D3. The results are shown as mean+SEM of three independent experiments, each normalized to its control and performed in triplicates. Cells from four different donors were used (*, $\mathrm{p}<0.05$, Mann-Whitney U test).

(TIF) 


\section{Acknowledgments}

We are grateful to the Orthopedic Surgeons (L. Seefried, U. Nöth and A. Steinert, Würzburg, Germany) who supplied us with explanted human femoral heads.

\section{References}

1. Christakos S, Dhawan P, Liu Y, Peng X, Porta A (2003) New insights into the mechanisms of vitamin D action. J Cell Biochem 88: 695-705.

2. Holick MF (2011) Vitamin D: evolutionary, physiological and health perspectives. Curr Drug Targets 12: 4-18.

3. Yoshizawa T, Handa Y, Uematsu Y, Takeda S, Sekine K, et al. (1997) Mice lacking the vitamin D receptor exhibit impaired bone formation, uterine hypoplasia and growth retardation after weaning. Nat Genet 16: 391-396.

4. van Leeuwen JP, van Driel M, van den Bemd GJ, Pols HA (2001) Vitamin D control of osteoblast function and bone extracellular matrix mineralization. Crit Rev Eukaryot Gene Expr 11: 199-226.

5. Razzaque MS, Lanske B (2006) Hypervitaminosis D and premature aging: lessons learned from Fgf23 and Klotho mutant mice. Trends Mol Med 12: 298-305.

6. Urakawa I, Yamazaki Y, Shimada T, Iijima K, Hasegawa H, et al. (2006) Klotho converts canonical FGF receptor into a specific receptor for FGF23. Nature 444: 770-774.

7. Kuro-o M, Matsumura Y, Aizawa H, Kawaguchi H, Suga T, et al. (1997) Mutation of the mouse klotho gene leads to a syndrome resembling ageing. Nature 390: 45-51.

8. Razzaque MS, Sitara D, Taguchi T, St-Arnaud R, Lanske B (2006) Premature aging-like phenotype in fibroblast growth factor 23 null mice is a vitamin Dmediated process. FASEB J 20: 720-722.

9. Sitara D, Razzaque MS, St-Arnaud R, Huang W, Taguchi T, et al. (2006) Genetic ablation of vitamin D activation pathway reverses biochemical and skeletal anomalies in Fgf-23-null animals. Am J Pathol 169: 2161-2170.

10. Ohnishi M, Nakatani T, Lanske B, Razzaque MS (2009) Reversal of mineral ion homeostasis and soft-tissue calcification of klotho knockout mice by deletion of vitamin D lalpha-hydroxylase. Kidney Int 75: 1166-1172.

11. Hesse M, Frohlich LF, Zeitz U, Lanske B, Erben RG (2007) Ablation of vitamin $\mathrm{D}$ signaling rescues bone, mineral, and glucose homeostasis in Fgf-23 deficient mice. Matrix Biol 26: 75-84.

12. Keisala T, Minasyan A, Lou YR, Zou J, Kalueff AV, et al. (2009) Premature aging in vitamin D receptor mutant mice. J Steroid Biochem Mol Biol 115: 91-97.

13. Kirkwood TB (2005) Understanding the odd science of aging. Cell 120: $437-447$.

14. Gui H, Kong Y, Zhang H (2012) Oxidative stress, mitochondrial dysfunction, and aging. J Signal Transduct 2012: 646354.

15. Johnson FB, Sinclair DA, Guarente L (1999) Molecular biology of aging. Cell 96: 291-302.

16. Kohrle J, Jakob F, Contempre B, Dumont JE (2005) Selenium, the thyroid, and the endocrine system. Endocr Rev 26: 944-984.

17. Abdallah BM, Kassem M (2009) The use of mesenchymal (skeletal) stem cells for treatment of degenerative diseases: current status and future perspectives. J Cell Physiol 218: 9-12.

18. Bianco P, Robey PG (2001) Stem cells in tissue engineering. Nature 414: $118-121$.

19. Christakos S, Dhawan P, Benn B, Porta A, Hediger M, et al. (2007) Vitamin D: molecular mechanism of action. Ann N Y Acad Sci 1116: 340-348.

20. Takahashi T, Nakamura K, Iho S (1997) Differentiation of myeloid cells and 1,25-dihydroxyvitamin D3. Leuk Lymphoma 27: 25-33.

21. Chen S, Law CS, Gardner DG (2010) Vitamin D-dependent suppression of endothelin-induced vascular smooth muscle cell proliferation through inhibition of CDK2 activity. J Steroid Biochem Mol Biol 118: 135-141.

22. Johnson CS, Hershberger PA, Bernardi RJ, McGuire TF, Trump DL (2002) Vitamin D receptor: a potential target for intervention. Urology 60: 123-130; discussion 130-121.

23. Gonzalez-Pardo V, Martin D, Gutkind JS, Verstuyf A, Bouillon R, et al. (2010) 1alpha,25-dihydroxyvitamin D3 and its TX527 analog inhibit the growth of endothelial cells transformed by Kaposi sarcoma-associated herpes virus G protein-coupled receptor in vitro and in vivo. Endocrinology 151: 23-31.

\section{Author Contributions}

Conceived and designed the experiments: FJ RE. Performed the experiments: BK BM CM MR CL NS SZ JS. Analyzed the data: BK BM RE FJ. Wrote the paper: BK BM RE FJ.

24. Dimri GP, Lee X, Basile G, Acosta M, Scott G, et al. (1995) A biomarker that identifies senescent human cells in culture and in aging skin in vivo. Proc Natl Acad Sci U S A 92: 9363-9367.

25. Dreier R, Gunther BK, Mainz T, Nemere I, Bruckner P (2008) Terminal differentiation of chick embryo chondrocytes requires shedding of a cell surface protein that binds 1,25-dihydroxyvitamin D3. J Biol Chem 283: 1104-1112.

26. Li J (2011) Quiescence regulators for hematopoietic stem cell. Exp Hematol 39: 511-520.

27. Brunet A, Sweeney LB, Sturgill JF, Chua KF, Greer PL, et al. (2004) Stressdependent regulation of FOXO transcription factors by the SIRT1 deacetylase. Science 303: 2011-2015.

28. Furukawa-Hibi Y, Yoshida-Araki K, Ohta T, Ikeda K, Motoyama N (2002) FOXO forkhead transcription factors induce $\mathrm{G}(2)-\mathrm{M}$ checkpoint in response to oxidative stress. J Biol Chem 277: 26729-26732.

29. Pierantozzi E, Gava B, Manini I, Roviello F, Marotta G, et al. (2011) Pluripotency regulators in human mesenchymal stem cells: expression of NANOG but not of OCT-4 and SOX-2. Stem Cells Dev 20: 915-923.

30. Jeong M, Piao ZH, Kim MS, Lee SH, Yun S, et al. (2009) Thioredoxininteracting protein regulates hematopoietic stem cell quiescence and mobilization under stress conditions. J Immunol 183: 2495-2505.

31. Liu Y, Elf SE, Mivata Y, Sashida G, Huang G, et al. (2009) p53 regulates hematopoietic stem cell quiescence. Cell Stem Cell 4: 37-48.

32. Spugnini EP, Campioni M, D'Avino A, Caruso G, Citro G, et al. (2007) Cellcycle molecules in mesothelioma: an overview. J Exp Clin Cancer Res 26: 443-449.

33. Endoh M, Kobayashi Y, Yamakami Y, Yonekura R, Fujii M, et al. (2009) Coordinate expression of the human pregnancy-specific glycoprotein gene family during induced and replicative senescence. Biogerontology 10: 213-221.

34. Byers SW, Rowlands T, Beildeck M, Bong YS (2011) Mechanism of action of vitamin $\mathrm{D}$ and the vitamin $\mathrm{D}$ receptor in colorectal cancer prevention and treatment. Rev Endocr Metab Disord.

35. Noth U, Osyczka AM, Tuli R, Hickok NJ, Danielson KG, et al. (2002) Multilineage mesenchymal differentiation potential of human trabecular bonederived cells. J Orthop Res 20: 1060-1069.

36. Ebert R, Ulmer M, Zeck S, Meissner-Weigl J, Schneider D, et al. (2006) Selenium supplementation restores the antioxidative capacity and prevents cell damage in bone marrow stromal cells in vitro. Stem Cells 24: 1226-1235.

37. Schutze N, Noth U, Schneidereit J, Hendrich C, Jakob F (2005) Differential expression of CCN-family members in primary human bone marrow-derived mesenchymal stem cells during osteogenic, chondrogenic and adipogenic differentiation. Cell Commun Signal 3: 5 .

38. Cristofalo VJ, Allen RG, Pignolo RJ, Martin BG, Beck JC (1998) Relationship between donor age and the replicative lifespan of human cells in culture: a reevaluation. Proc Natl Acad Sci U S A 95: 10614-10619.

39. Kern S, Eichler H, Stoeve J, Kluter H, Bieback K (2006) Comparative analysis of mesenchymal stem cells from bone marrow, umbilical cord blood, or adipose tissue. Stem Cells 24: 1294-1301.

40. LeBel CP, Ischiropoulos H, Bondy SC (1992) Evaluation of the probe 2',7'dichlorofluorescin as an indicator of reactive oxygen species formation and oxidative stress. Chem Res Toxicol 5: 227-231.

41. Royall JA, Ischiropoulos H (1993) Evaluation of 2',7'-dichlorofluorescin and dihydrorhodamine 123 as fluorescent probes for intracellular $\mathrm{H} 2 \mathrm{O} 2$ in cultured endothelial cells. Arch Biochem Biophys 302: 348-355.

42. Schupp N, Schmid U, Rutkowski P, Lakner U, Kanase N, et al. (2007) Angiotensin II-induced genomic damage in renal cells can be prevented by angiotensin II type 1 receptor blockage or radical scavenging. Am J Physiol Renal Physiol 292: F1427-1434.

43. Pittenger MF, Mackay AM, Beck SC, Jaiswal RK, Douglas R, et al. (1999) Multilineage potential of adult human mesenchymal stem cells. Science 284: 143-147.

44. Schilling T, Noth U, Klein-Hitpass L, Jakob F, Schutze N (2007) Plasticity in adipogenesis and osteogenesis of human mesenchymal stem cells. Mol Cell Endocrinol 271: 1-17. 